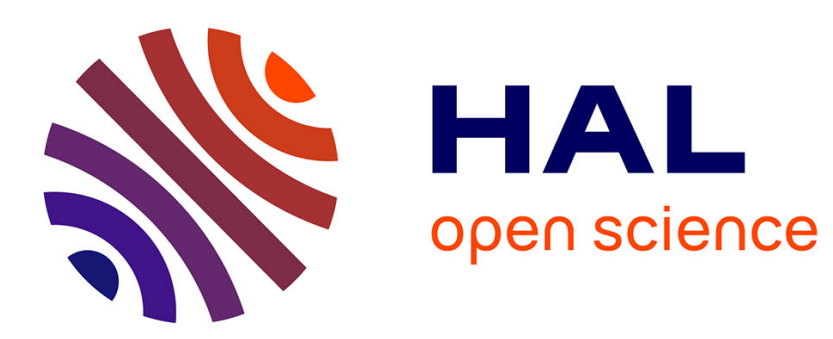

\title{
The Effect of Nonstoichiometry on Microwave Absorbing Properties of Ni-Zn Ferrites
}

\author{
S.-S. Kim, I. Choi
}

\section{To cite this version:}

S.-S. Kim, I. Choi. The Effect of Nonstoichiometry on Microwave Absorbing Properties of Ni-Zn Ferrites. Journal de Physique IV Proceedings, 1997, 07 (C1), pp.C1-423-C1-424. 10.1051/jp4:19971171. jpa-00254818

\section{HAL Id: jpa-00254818 https://hal.science/jpa-00254818}

Submitted on 1 Jan 1997

HAL is a multi-disciplinary open access archive for the deposit and dissemination of scientific research documents, whether they are published or not. The documents may come from teaching and research institutions in France or abroad, or from public or private research centers.
L'archive ouverte pluridisciplinaire HAL, est destinée au dépôt et à la diffusion de documents scientifiques de niveau recherche, publiés ou non, émanant des établissements d'enseignement et de recherche français ou étrangers, des laboratoires publics ou privés. 


\title{
The Effect of Nonstoichiometry on Microwave Absorbing Properties of Ni-Zn Ferrites
}

\author{
S.-S. Kim and I.G. Choi* \\ Department of Materials Engineering, Chungbuk National University, Cheongju 360-763, Korea \\ * Department of Radio Engineering, Chungbuk National University, Cheongju 360-763, Korea
}

\begin{abstract}
Microwave absorbing properties of the nonstoichiometric compounds of $\mathrm{N} i \mathrm{Zn}$ ferrites with excess $\mathrm{Fe}_{2} \mathrm{O}_{3}$ are investigated.

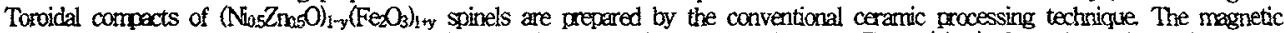
permeability and delectric constant are greatly dependent upon the amount of excess $\mathrm{Fe}_{2} \mathrm{O}_{3}(\mathrm{y}>0)$. Both the real and imaginary components of permeability decrease as the excess $\mathrm{Fe}_{2} \mathrm{O}_{3}$ increases $\mathrm{On}$ the other hand, the dielectric constant increases with the increase of excess $\mathrm{Fe}_{3} \mathrm{O}_{3}$. The combined effect of high dielectric constant and low permeability results in a lower-frequency impedance matching. The plate thickness at the zero-reflection frequency is predicted using the approximated impedance-matching relationship betwen wavelength and material parameters.
\end{abstract}

\section{INTRODUCTION}

The sintered plate of $\mathrm{Ni}-\mathrm{Zn}$ fenite is widely used as an electromagnetic wave absorber in the VHF/UHF region [1,2]. The main task in designing of the ferrite tile absomber used in those frequency band is to obtain the superior absorbing properties especially in the low frequencies. One of the approach to solve this problem is to endow the ferrite tiles with high dielectric constant and low permeability. Based on this background, the nonstoichiometric compounds of $\mathrm{Ni}-\mathrm{Zn}$ ferrite with excess Fe $\mathrm{O}_{3}$ are chosen and their microwave absorbing properties are investigated. It is expected that the increased ferrous ion content from the excess Fe2 $\mathrm{O}_{3}$ is effective in increasing the dielectric constant and thereby, results in an impedance-matching at the lower frecuency.

\section{EXPERIMENTALS}

The specimens of $\left(\mathrm{Ni}_{5} \mathrm{Zn}_{05} \mathrm{O}_{1-y}\left(\mathrm{Fe}_{2} \mathrm{O}_{3}\right)_{1+y}\right.$ spinels were prepared by conventional ceramic processing technique, where y denotes the excess of iron. The toroidal compacts were sintered at $1250{ }^{\circ} \mathrm{C}$ for $2 \mathrm{hrs}$ in air. The complex permeability and permittivity and microwave absorbing properties were measured by the reflection/transmission technique described in the earlier paper [3].

\section{RESULTS AND DISCUSSION}

Fig.1 shows the complex permeability $\left(\mu_{\mathrm{r}}^{\prime}-\mathrm{j} \mu_{\mathrm{r}}^{\prime \prime}\right)$ and permittivity $\left(\varepsilon_{\mathrm{r}}^{\prime}-\mathrm{j} \varepsilon_{\mathrm{r}}^{\prime \prime}\right)$ spectra determined in $\left(\mathrm{Ni}_{0.5} \mathrm{Zn}_{0.5} \mathrm{O}\right)_{1-\mathrm{y}}\left(\mathrm{Fe} \mathrm{O}_{3}\right)_{1+\mathrm{y}}$ samples. As shown in Fig.1(a) and Fig.1(b), both $\mu_{\mathrm{r}}{ }^{\prime}$ and $\mu_{\mathrm{r}}{ }^{\prime \prime}$, which are decreasing functions of the frecruency, decrease with the increase of the iron-excess content $(y)$. In the case of stoichiometric compound $(y=0), \mu_{r}^{\prime}$ is 45 and $\mu_{r}^{\prime \prime}$ is 60 at $130 \mathrm{MHz}$. On the while, in the iron-excess sample with $y=0.16, \mu_{r}^{\prime}$ and $\mu_{r}^{\prime \prime}$ decreases to 14 and 25 , respectively.

On the contrary to the magnetic permeability, dielectric constant increases with the increase of excess iron content as shown in Fig.1(c). As compared to the dielectric constant of stoichiometric compound ( $\varepsilon_{\mathrm{r}}^{\prime}=12$ ), a much higher value of $\varepsilon_{\mathbf{r}}^{\prime}$ (about 32) is observed in the sample with $y=0.08$. The high dielectric constant is attributed to the more enhanced electrical conduction with the increase in ferrous ion $\left(\mathrm{Fe}^{+2}\right)$ content in the spinel lattice. The dielectric loss $\left(\varepsilon_{\mathrm{r}}^{\prime \prime}\right)$ was small, but has a tendency to increase with the increase of excess iron. For the sample of $y=0.08$, the value of $\varepsilon_{\mathrm{r}}{ }^{\prime \prime}$ is about 5 .

Fig.2 shows the microwave reffectance calculated from the measured $\mu_{\mathrm{r}}$ and $\varepsilon_{\mathrm{r}}$. The calculation procedure was described in the previous paper [4]. A specified frequency with the minimum reflection loss moves to lower frequency as the excess iron increases $(600 \mathrm{MHz}$ at $\mathrm{y}=0,240 \mathrm{MHz}$ at $\mathrm{y}=0.08)$ and the corresponding absorber thickness increases $(3.9 \mathrm{~mm}$ at $y=0,5.7 \mathrm{~mm}$ at $y=0.08)$.

For a microwave absorbing layer terminated by a metal, a zero-reflection condition is determined by a proper combination of material parameters and absorber thickness, which is given by

$$
\sqrt{\mu_{r} / \varepsilon_{r}} \tanh \left[j(2 \pi d / \lambda) \sqrt{\mu_{r} \varepsilon_{r}}\right]=1
$$

where $d$ is thickness and $\lambda$ is wavelength. For the absonbers with high magnetic loss $\left(\mu_{\mathbf{r}}{ }^{\prime}\left\langle\mu_{\mathbf{r}}{ }^{\prime}\right\rangle\right.$ and low dielectric loss as in the case of femite tiles, the parameters requirements for zero-reflection can be apgroximated by the simple relationships [1,2] : 


$$
\begin{gathered}
d / \lambda=1 / 2 \pi \mu_{r}{ }^{\prime \prime} \\
\mu_{r}{ }^{\prime}=\varepsilon_{r} / \beta
\end{gathered}
$$

In the present study, Eq.(2) can also be used in determining the microwave absorbing properties. Fig. 3 shows the illustrations of determining the absorber thickness and zero-reflection frequency. For the stoichiometric compound $(y=0)$, El, (2) is satisfied at a frequency of $600 \mathrm{MHz}$ and where the absorber thickness is $3.9 \mathrm{~mm}$ (Fig.3(a)). The lower zero-reflection frequency and larger absorber thickness in the iron-excess sample ( $y=0.08$ ) can be explained in Fig.3(b). Zero-reflection frequency and absorber thickness are found to be $245 \mathrm{MHz}$ and $5.7 \mathrm{~mm}$, respectively. The predictions are in good agreement with the result of reflection loss shown in Fig.2.

The impedance-matching at a lower frequency in the iron-excess ferrite is attributed to the lower value of $\mu_{r}{ }^{\prime}$ and higher value of $\varepsilon_{\mathrm{r}}{ }^{\prime}$, which is arising from the increase in $\mathrm{Fe}^{+2}$ content in the spinel lattice. It can thus be suggested that the compositional control of nonstoichimetry is one of the convenient ways to control the microwave absorbing properties of $\mathrm{Ni}$ - $\mathrm{Zn}$ ferrites.
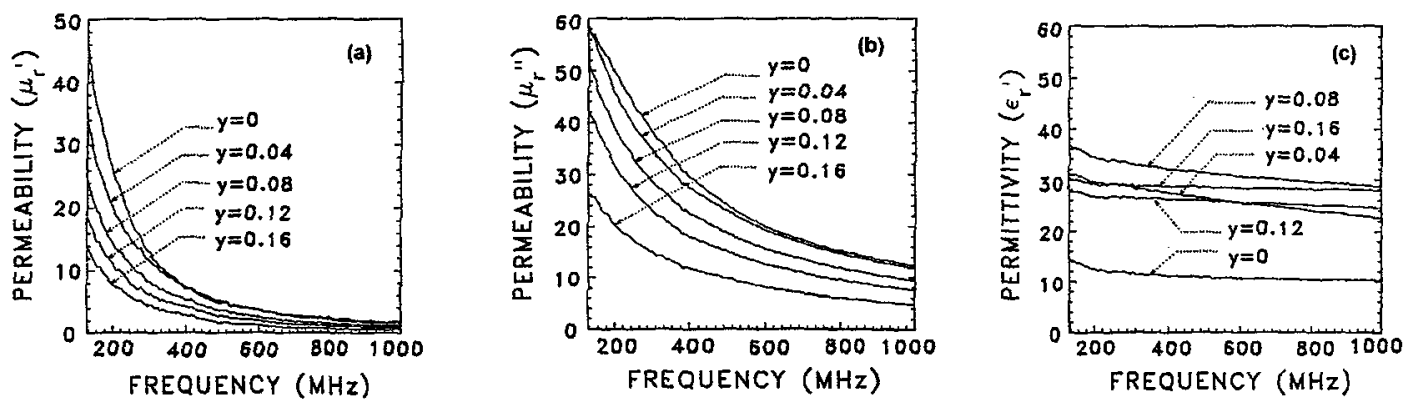

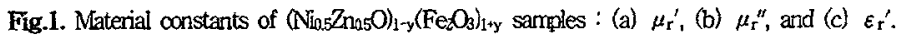

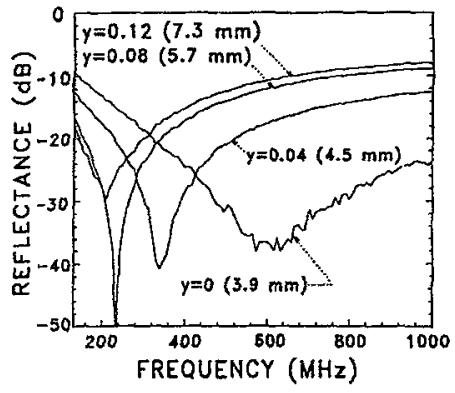

Fig.2. Microwave reflectance determined in $\left(\mathrm{Ni}_{0} \mathrm{Z}_{\mathrm{n}} \mathrm{O}_{5} \mathrm{O}\right)_{1-} \mathrm{y}\left(\mathrm{Fe} \mathrm{O}_{3}\right)_{1+y}$ samples.
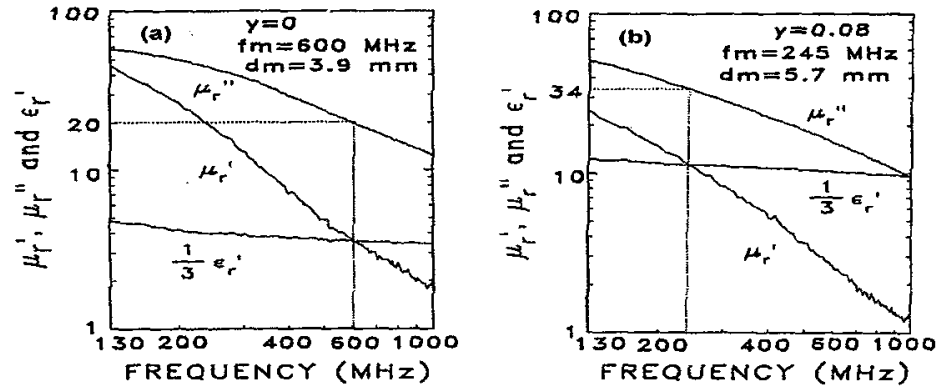

Fig 3. Prediction of zero-reflection freanency and absorber thickness in

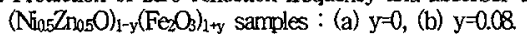

\section{CONCLUSION}

It was demonstrated that the microwave absorbing properties (especially, absorbing frequency band) of $\mathrm{Ni}-\mathrm{Zn}$ ferrite tiles can be controlled by the nonstoichiometry (excess of iron) of the spinel compound. The increase of excess iron resulted in the lower magnetic permeability and higher dieletric constant which, in turn, produced an impedance-matching at the lower frequency. The plate thickness was then determined using the approximated impedance-matching relationship between wavelength and material parameters.

\section{Acknowledgements}

This paper was supported by nondirected research fund, Korea Research Foundation, 1996.

\section{References}

[1] HMMusal,Jr. and H.T.Hahn, IEEE Trans. on Mag., 25 (1989) 3851-3853.

[2] KAkita, FERRITES: Proceeding of the International Conference, Japan (1980) pp.885-889.

[3] S.S.Kin, D.H.Han and S.B.Cho, IEICE Trans. on Mag., 30 (1994) 4554-4556.

[4] S.S.Kim, S.B.Jo, K.IGueon, KKChoi, J.MKim and K.S.Chum, IFEE Trans. on Mag., 27 (1991) 5462-5464 